\title{
Compatibilization of Poly(butylene terephthalate)/Metallocenic Poly(ethylene-octene) Blends by Means of Poly(ethylene-co-glycidyl methacrylate)
}

\author{
Asier ARÓstegui and Jon NAZÁBAL ${ }^{\dagger}$ \\ Departamento de Ciencia y Tecnología de Polímeros and Instituto de Materiales Poliméricos "POLYMAT", \\ Facultad de Ciencias Quimicas UPV/EHU, P. O. Box 1072, San Sebastián 20080, Spain
}

(Received July 30, 2002; Accepted October 23, 2002)

\begin{abstract}
Super-tough poly(butylene terephthalate) (PBT) based blends were obtained by melt blending PBT with $20 \mathrm{wt} \%$ poly(ethylene-octene) copolymer (PEO), and varying amounts of poly(ethylene-co-glycidyl methacrylate) (EGMA) as a compatibilizer. Partially reacted EGMA dissolved completely, mainly in the PBT-rich phase, up to 4\% EGMA, at which point a crystalline EGMA phase appeared. The reaction and the consequent compatibilization led to a decrease in the particle size and to an improvement in the adhesion between the components. Two percent EGMA was the minimum content required to reach maximum super-toughness, that also corresponded to the maximum ductility. The inter-particle distance $(\tau)$ was the parameter that controlled super-toughness. The study of the parameters that $\tau_{\mathrm{c}}$ depends on, showed that $\tau_{\mathrm{c}}$ was independent of the modulus of the dispersed phase $\left(E_{\mathrm{d}}\right)$ over the $\tau_{\mathrm{c}}$ range studied. However, the dependence of $\tau_{\mathrm{c}}$ on adhesion at the interphase was seen by means of the comparison of the $\tau_{\mathrm{c}}$-interfacial tension relationship of this blend with those of previous studies.

KEY WORDS Poly(butylene terephthalate) / Poly(ethylene-octene) Copolymer / Poly(ethylene-coglycidyl methacrylate) / Super-Toughness / Critical Inter-Particle Distance /
\end{abstract}

Rubber toughening is the traditional method, ${ }^{1,2}$ of improving the impact strength of thermoplastics. The improvement obtained is significant, but recently much higher increases leading to so-called super-toughness, have been attained by compatibilization, ${ }^{3-6}$ for instance, with maleic anhydride, epoxy or compounds with amine groups. Thermoplastics for which super-toughness was achieved include poly(butylene terephthalate) (PBT), ${ }^{3,7-10}$ polyamides, ${ }^{5,11-15}$ amorphous copolyester, ${ }^{6}$ polyoxymethylene, ${ }^{10}$ poly(phenylene sulfide), ${ }^{10}$ poly(vinyl chloride) ${ }^{16}$ and high density polyethylene. ${ }^{17}$

Of the variables that influence toughening, the particle size of the rubber dispersed phase was considered to be the main parameter. ${ }^{2,5,11,18,19}$ However, more recently, the mean inter-particle distance between two neighboring particles $(\tau)$ has been proposed ${ }^{14}$ as the factor that controls super-toughness, that should appear when $\tau$ is below a critical value $\left(\tau_{\mathrm{c}}\right)$. Firstly, it was proposed that $\tau_{\mathrm{c}}$ was a characteristic of a given matrix, ${ }^{14,17,20}$ but subsequent studies demonstrated that there are extrinsic parameters ${ }^{10,20-24}$ such as the test temperature, strain rate and mode of deformation that influence the value of $\tau_{\mathrm{c}}$. Intrinsic parameters $3,7,8,10,16,25$ such as the crystallinity of the matrix, type and modulus of the rubber, the ratio of the modulus of the matrix to that of the rubbery dispersed phase $\left(E_{\mathrm{m}} / E_{\mathrm{d}}\right)$, and adhesion between the components, have been also proposed to influence $\tau_{\mathrm{c}}$. The influence of extrinsic parameters is clearly seen. However, that of intrinsic parameters is not, because with the exception of adhesion, the change of one intrinsic parameter, leads to the change of another, making it difficult to determine the parameter to which the changes have to be attributed.

Super-tough PBT based blends were obtained using both maleinized poly(ethylene-octene) copolymer $(\mathrm{mPEO})^{3}$ and a difunctional epoxy resin. ${ }^{7,8}$ In these studies the $E_{\mathrm{m}} / E_{\mathrm{d}}$ ratio $^{3}$ and the adhesion between the components ${ }^{7,8}$ were proposed as intrinsic parameters that influence $\tau_{\mathrm{c}}$, and as a consequence parameters to be controlled to achieve super-toughness. However, the parameters that control super-toughness and how they work are far from being known, and much more work is needed to fully understand the reasons and conditions that lead to super-toughness. In this way, the possibility of obtaining new PBT based super-tough blends by a new compatibilizing method, besides its intrinsic importance, would offer a new $\tau_{\mathrm{c}}$ value that could be used to find out the intrinsic parameters of the blend that influence $\tau_{\mathrm{c}}$.

The interactions between PBT and PEO can be modified using poly(ethylene-co-glycidyl methacrylate) (EGMA) because its epoxy functional groups interact or react with the hydroxyl or carboxyl end groups of PBT. EGMA has been used in polyester/polyolefin

${ }^{\dagger}$ To whom correspondence should be addressed (Tel: +34-943-018218, Fax: +34-943-212236, E-mail: popnaetj@sq.ehu.es). 
blends. ${ }^{26-30}$ Provided super-toughness is obtained, the comparison of the new $\tau_{\mathrm{c}}-E_{\mathrm{d}}$ value with those of previous blends, and the comparison of the $\tau_{\mathrm{c}}$-adhesion value of this study with those of $\mathrm{PBT} / \mathrm{PEO}^{3,7,8}$ blends compatibilized in other ways could give experimental information about the parameters $\tau_{\mathrm{c}}$ depends on.

The purpose of this study is to examine the possibility of obtaining super-tough PBT based blends by melt blending followed by injection molding PBT with both $20 \mathrm{wt} \%$ PEO, and variable amounts of EGMA as a compatibilizer. The blends were characterized by differential scanning calorimetry (DSC), dynamic mechanical thermal analysis (DMTA), contact angle measurements, torque measurements, Fourier transform infrared spectroscopy (FT-IR) and scanning electron microscopy (SEM). The mechanical properties were measured by means of tensile and impact tests. The results on the impact strength tests and the mean particle size of the blends were used to determine $\tau_{\mathrm{c}}$. The corresponding $\tau_{\mathrm{c}}-E_{\mathrm{d}}$ and $\tau_{\mathrm{c}}$-adhesion pairs were compared with those obtained with other compatibilizers in PBT/PEO and other blends.

\section{EXPERIMENTAL}

The PBT used in this work was CRASTIN S600F10 (DuPont) $\left(\bar{M}_{\mathrm{n}}=20400\right)$. PEO was ENGAGE EG 8200 (DuPont-Dow) $\left(\bar{M}_{\mathrm{n}}=82900\right)$. EGMA (LOTADER AX8840, containing $8 \mathrm{wt} \%$ glycidyl methacrylate (GMA)) was kindly supplied by Atofina. PBT $(4 \mathrm{~h}$ at $120^{\circ} \mathrm{C}$ ), and PEO and EGMA $\left(6 \mathrm{~h}\right.$ at $\left.60^{\circ} \mathrm{C}\right)$ were dried before processing in an air oven to avoid possible moisture-induced degradation reactions. The PBT/PEO ratio in the blends was $80 / 20$. The EGMA content with respect to a $100 \% \mathrm{PBT} / \mathrm{PEO}$ blend changed from 0 to $10 \mathrm{wt} \%$.

Blending of PBT, PEO, and EGMA at the desired compositions was carried out in a Collin twin-screw extruder-kneader (type ZK25, L/D ratio 24, screw diameter $25 \mathrm{~mm}$ ). PBT/PEO-EGMA blends were processed at $250^{\circ} \mathrm{C}$, except the $80 / 20-0$ blend, which was processed at $225^{\circ} \mathrm{C}$ because of its low melt strength at $250^{\circ} \mathrm{C}$. The rotor speed was $50 \mathrm{rpm}$. The rod extrudate was cooled in a water bath and then pelletized. Injection molding was carried out in a Battenfeld reciprocating screw injection molding machine to obtain tensile (ASTM D638, type IV, thickness $3.2 \mathrm{~mm}$ ) and impact (ASTM D256, thickness $3.2 \mathrm{~mm}$ ) specimens. The screw had a diameter of $18 \mathrm{~mm}$ and a $\mathrm{L} / \mathrm{D}$ ratio of 17.8 . The melt temperature was $250^{\circ} \mathrm{C}$ (for neat PEO and EGMA $190^{\circ} \mathrm{C}$ ) and the mold temperature was $60^{\circ} \mathrm{C}$ (for neat PEO and EGMA $15^{\circ} \mathrm{C}$ ). The injection speed and pressure were $7 \mathrm{~cm}^{3} \mathrm{~s}^{-1}$ and $120 \mathrm{MPa}$, respectively.
The melting behavior was studied by DSC using a PerkinElmer DSC-7 calorimeter. An indium sample was used as a reference. The samples were first heated from $10^{\circ} \mathrm{C}$ up to $270^{\circ} \mathrm{C}$ at $20^{\circ} \mathrm{C} \mathrm{min}^{-1}$, then cooled at the same rate, and reheated. The melting temperature $\left(T_{\mathrm{m}}\right)$ and the enthalpy were determined in the first heating scan from the maxima and the area of the peaks, respectively. The phase structure was studied by dynamic mechanical analysis performed on a Polymer Laboratories DMTA that provided the plot of the loss tangent $(\tan \delta)$ against temperature. The scans were carried out in single cantilever mode at a constant heating rate of $2{ }^{\circ} \mathrm{C} \mathrm{min}^{-1}$ and a frequency of $1 \mathrm{~Hz}$, from $-130^{\circ} \mathrm{C}$ to roughly $100^{\circ} \mathrm{C}$.

The torque of mixing of pure PBT and PEO with and without 2\% EGMA, and those of the PBT/PEO 80/20 blend with 0,2 , and 5\% EGMA contents were measured in a Brabender Plasticorder at $250^{\circ} \mathrm{C}$ and $50 \mathrm{rpm}$. The operation was maintained for roughly $20 \mathrm{~min}$.

The possible reactions between PBT, PEO, and EGMA were studied by FT-IR in the injected specimens using a Nicolet 5 DXC spectrophotometer. The contact angle measurements were carried out on a CAM 100 goniometer (KSV) on injection molded specimens, using water and ethylene glycol. The interfacial tension was calculated by the two-liquid Harmonic Method ${ }^{31}$ measuring the contact angle of two liquids on the surface of PBT/EGMA and PEO/EGMA blends. At least five drops were examined and averaged for each contact angle result. The mean standard deviation of the measurement was $2-3^{\circ}$ which led to an error in the interfacial tension values of approximately $20 \%$.

The surfaces of cryogenically fractured specimens were observed by SEM after gold coating. A Hitachi S-2700 electron microscope was used at an accelerating voltage of $15 \mathrm{kV}$. The particle size of the rubber was measured in representative zones of the cryogenically fractured impact specimens. The weight-average particle size, $\bar{d}_{\mathrm{w}}$, was calculated from a minimum of 200 particles as

$$
\bar{d}_{\mathrm{w}}=\frac{\sum n_{\mathrm{i}} d_{\mathrm{i}}^{2}}{\sum n_{\mathrm{i}} d_{\mathrm{i}}}
$$

where $n$ is the number of particles with size $d^{2,21,22}$

The tensile tests were carried out using an Instron 4301 tensile tester at a cross-head speed of 10 $\mathrm{mm} \mathrm{min}{ }^{-1}$ and at $23 \pm 2{ }^{\circ} \mathrm{C}$. The Young's modulus was determined by means of an extensometer. The yield stress and ductility, measured as the break strain, were determined from the load-displacement curves. The elongation at break was determined from the crosshead travel rate, assuming a gauge length of $64 \mathrm{~mm}$. Izod impact tests were carried out on notched specimens us- 
ing a CEAST 6548/000 pendulum. The notch (depth $2.54 \mathrm{~mm}$ and radius $0.25 \mathrm{~mm}$ ) was machined after injection molding. A minimum of five tensile specimens and ten impact specimens was tested for each reported value.

\section{RESULTS AND DISCUSSION}

\section{Solid-State Behavior}

The phase structure of PBT/PEO-EGMA blends was studied by DMTA. In the 80/20 PBT/PEO blend, two pure amorphous phases were present. ${ }^{3}$ Therefore, only the effects of the presence of EGMA will be studied. Figure 1 shows the DMTA scans of pure PBT and EGMA, of binary PBT and PEO blends with 2\% EGMA, and of the 80/20 PBT/PEO blends with 0, 2, and $10 \%$ EGMA contents. Neither the $T_{\mathrm{g}}$ of pure PEO (at $-36^{\circ} \mathrm{C}$ ), nor its secondary transition $\left(\right.$ at $-121^{\circ} \mathrm{C}$ ) changed with the addition of EGMA, so the DMTA scan of pure PEO is not shown.

As can be seen, when the scans of the ternary blends with different EGMA contents are compared, the $T_{\mathrm{g}}$ of PEO could not be determined, probably because of its low intensity. A possible presence of reacted EGMA in the PEO phase will be discussed later with reference to torque measurements. Moreover, the $T_{\mathrm{g}}$ of EGMA was not seen in the scan of the 80/20-10 blend, indicating the absence of an amorphous EGMA phase. Finally, on EGMA addition, although the secondary transition of PBT remained constant at $-78^{\circ} \mathrm{C}$, the position of the $T_{\mathrm{g}}$ of PBT changed from $58^{\circ} \mathrm{C}$ in the $80 / 20-0$ blend to $54^{\circ} \mathrm{C}$ in the blends whatever the EGMA content. This indicates the presence of a PBT-rich phase with some EGMA. The presence of EGMA in the PBT-rich phase can be either as a miscibilized or reacted product; this will be discussed later.

The melting behavior of PBT/PEO-EGMA blends was studied by DSC. Figure 2 shows the first DSC scans of pure PBT and EGMA, and those of the 80/20 blend with 0,2 , and 10\% EGMA. As can be seen, no crystallization exotherm was observed in spite of the rapid cooling in the injection mold. With respect to the crystalline phase of PBT, as observed ${ }^{\beta, 7}$ previously, and as seen in the scan of the 80/20-0 blend of Figure 2, the presence of PEO did not disturb the melting process of PBT. It was the same in the case of EGMA, because the $T_{\mathrm{m}}$ of PBT $\left(225^{\circ} \mathrm{C}\right)$ did not change with the EGMA content, probably due to the slight EGMA presence. Finally, although constant in a second scan, the crystallization level of PBT in the blends in the first scan slightly decreased upon EGMA addition from $32 \%$ (neat PBT and $80 / 20-0$ blend) to $26 \%$ (blends with EGMA).

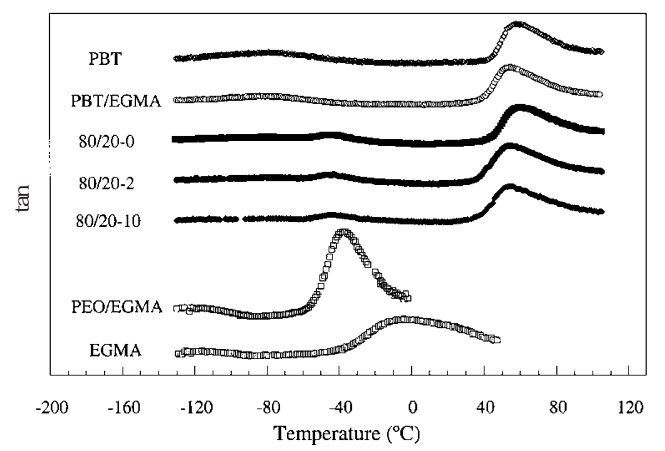

Figure 1. DMTA scans of pure PBT and EGMA, of binary PBT and PEO with $2 \%$ EGMA, and of 80/20 blends with 0,2 , and $10 \%$ EGMA contents. To aid clarity, the curves are shifted on the vertical axis.

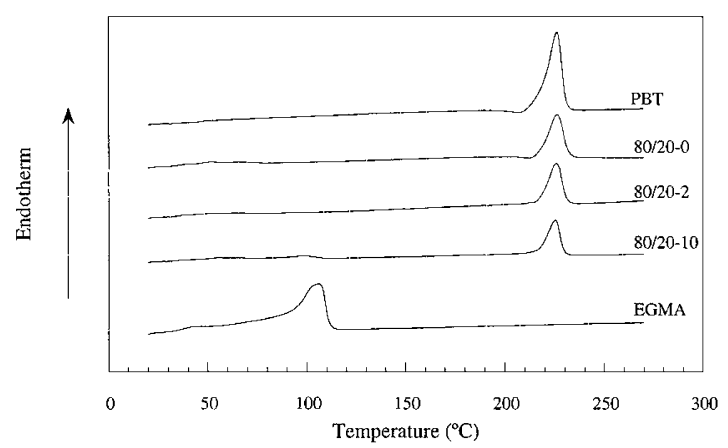

Figure 2. First DSC heating scans of the pure PBT and EGMA, and of the $80 / 20$ blends with 0,2 , and 10\% EGMA contents. To aid clarity, the curves are shifted on the vertical axis.

With respect to the crystalline EGMA phase, the melting of EGMA was seen only in the blends with EGMA contents of $4 \%$ or more. This indicates that EGMA contents below $4 \%$ were fully miscibilized in the blends. Moreover, as can also be seen in Figure 2, the $T_{\mathrm{m}}$ of EGMA decreased from 106 (pure EGMA) to $100^{\circ} \mathrm{C}(80 / 20-10$ blend $)$ and the crystallinity from 26 (pure EGMA) to $14 \%$ (80/20-10 blend). These differences could be attributed either to the different processing temperatures used for pure EGMA and PBT/PEOEGMA blends or to PBT hindering the crystallization of EGMA. A similar behavior has been observed in polyamide/EGMA blends, ${ }^{32}$ where the processing temperature did not change. Therefore, PBT probably hindered the crystallization of EGMA.

The possibility of reactions between EGMA and either of the two components of the PBT/PEO blend was tested by FT-IR. The FT-IR spectrum of the blend with EGMA was similar to that obtained by combining the weighted spectra of the pure components. This indicated that, if chemical reactions took place, their extent was small. The possibility of reaction was also studied by torque measurements in an internal mixer, that have been used extensively to detect the possibility of chemical reactions in the melt state ${ }^{7,33}$ because 


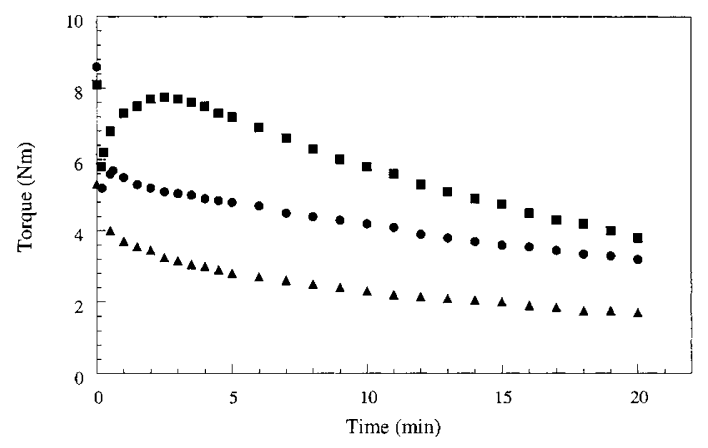

Figure 3. Torque $v$ s. time of PBT/PEO $80 / 20$ blends with 0 $(\boldsymbol{\Delta}), 2(\bullet)$, and 5\% (•) EGMA contents.

the grafted or cross-linked reaction products lead to a prompt torque increase that makes the torque behavior very sensitive to these reactions. For this reason, in Figure 3 the torque curves of the PBT/PEO 80/20 blend with 0,2 , and 5\% EGMA contents are shown. As can be seen, the torque of the 80/20-0 blend decreased monotonously with mixing time. However, the torques of the blends with 2 and 5\% EGMA content increased after a short mixing time, reaching a maximum value at approximately 1 and $2.5 \mathrm{~min}$, respectively. Moreover, the torque difference between the blends with EGMA and the 80/20 blend, and therefore the reaction level, was higher when the EGMA content increased. This proves that reactions took place in the internal mixer and that, despite the FT-IR results, probably also took place in the extruded-injected blends. The blends were melted at the same temperature in both procedures, and the reactions appeared in Figure 3 after a mixing time shorter than that used to produce the blends. The short time to reaction start is probably due to the high reactivity of the epoxy functional groups.

To find out which of the two components of the blend reacted with EGMA, binary PBT and PEO blends with 2\% EGMA, and the neat PBT and PEO as a reference, were obtained in the internal mixer, and the corresponding torque curves are shown in Figure 4. As can be seen, the torques of melt-phase PBT (open circles) and PEO (open squares) decreased monotonously with mixing time, probably as a consequence of thermal and/or mechanical degradation. However, the torque difference between the torque curve of PBT and that of PBT with $2 \%$ EGMA started to increase after about 2 min, but $10 \mathrm{~min}$ were necessary in the case of PEO binary blends with 2\% EGMA content to move away from the torque curve of pure PEO. Then, the torque differences disappeared, probably as a consequence of degradation. Therefore, as the extrusion-injection process is carried out in only roughly $5 \mathrm{~min}$, the chemical reactions are probably more developed in PBT because of the short time they need to take place.

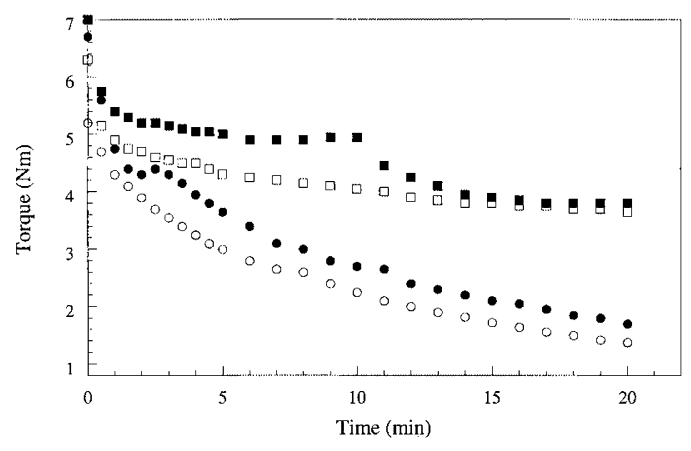

Figure 4. Torque $v s$. time of $\operatorname{PBT}(O, \bullet)$ and $\operatorname{PEO}(\square, \boldsymbol{\square})$ without (outline symbols) and with 2\% EGMA (filled solid symbols).

\section{Morphology}

The cryofractured surfaces of the injection molded impact specimens were observed by SEM. A fine layer (about $100-150 \mu \mathrm{m}$ ) with elongated rubber particles covered the specimens, ${ }^{3,7,8,34,35}$ whatever the EGMA content. The likely effects of such a fine layer on the mechanical properties are negligible due to its low thickness, so it will not be considered in the discussion of the morphology. In the rest of the transverse section, the morphologies close to the outside and in the inner part of the specimen (roughly two thirds of the specimen) were slightly different. This difference was probably because the cooling was faster and/or the shear rate much higher in the outside part than in the inner part, and as a consequence the possibility of coalescence decreased. ${ }^{3,7,8}$ However, the morphological changes of both parts followed the same trends. Therefore, only the morphology of the inner part of the specimens will be presented.

Figure 5 shows the cryogenically fractured surfaces of the inner part of the impact specimens of the blends with 0 (a), 1 (b), 2 (c), and 10\% (d) EGMA contents. As can be seen when Figures $5 \mathrm{a}$ and $5 \mathrm{~b}$ are compared, the particle size clearly decreased on EGMA addition. The decrease was from 2.63 (80/20-0 blend) to $1.49 \mu \mathrm{m}$ (80/20-1 blend) to $1.30 \mu \mathrm{m}(80 / 20-2$ blend) to $0.96 \mu \mathrm{m}$ (80/20-10 blend). This decrease in the particle size with EGMA addition indicates that compatibilization took place, and from a morphological point of view, increased with the EGMA content. This decrease in the particle size agrees with the interactions at the interface expected as a consequence of the reactions observed in Figures 3 and 4. Larger EGMA contents should lead to an increase in the degree of reaction. This agrees with the larger torque increases at larger EGMA contents seen in Figure 3.

As can also be seen in Figure 5, the surfaces of both the particles and the holes are clear. This indicates that the adhesion level between PBT and PEO was poor, but as can be seen in Figures $5 \mathrm{~b}-5 \mathrm{e}$, in addition to holes 


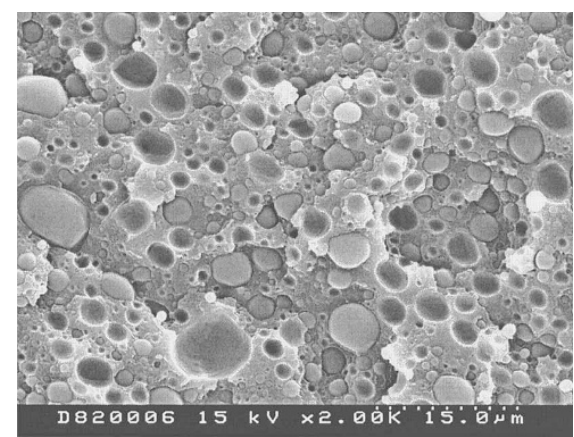

(a)

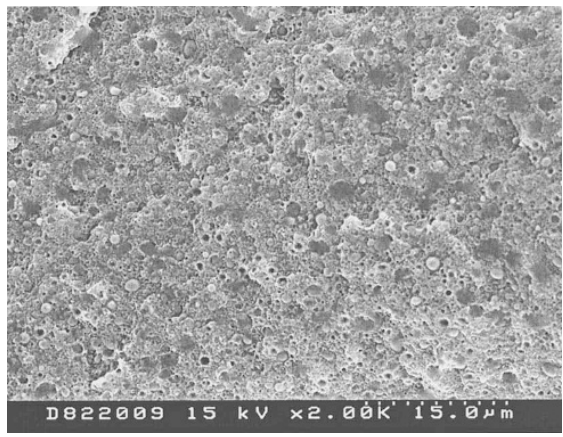

(c)

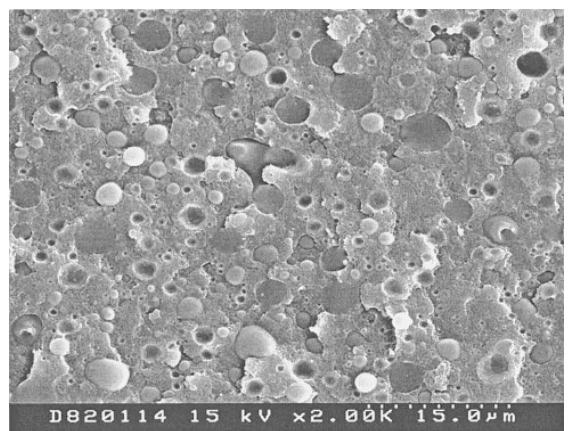

(b)

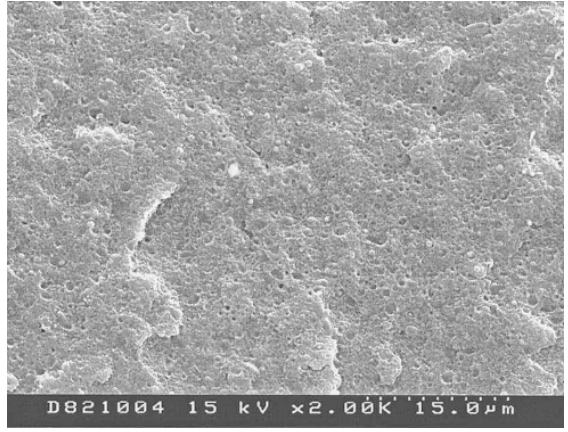

(d)

Figure 5. Cryofractured surface of the inner zone of the injection molded impact specimens of PBT/PEO 80/20 blends with 0 (a), 1 (b), 2 (c), and 10\% (d) EGMA contents.

Table I. Interfacial tension (measured by means of the contact angle) between PBT/EGMA and PEO/EGMA as a function of EGMA content

\begin{tabular}{cc}
\hline $\begin{array}{c}\text { EGMA content } \\
(\%)\end{array}$ & $\begin{array}{c}\gamma_{12} \\
\left(\mathrm{mN} \mathrm{m}^{-1}\right)\end{array}$ \\
\hline 0 & 1.76 \\
1 & 1.30 \\
2 & 0.59 \\
4 & 0.68 \\
10 & 0.51 \\
\hline
\end{tabular}

and particles, a number of broken particles were seen, proving that adhesion exists, and that its level improved as the EGMA content increased.

To investigate the reasons for the improved compatibility of the PBT/PEO-EGMA blends, and for the better adhesion of the blends observed with EGMA, the interfacial tension $\left(\gamma_{12}\right)$ between PBT/EGMA and PEO/EGMA with different EGMA contents was measured by means of the contact angle, and the corresponding results are shown in Table I. As can be seen, the $\gamma_{12}$ between PBT and PEO $\left(1.76 \mathrm{mN} \mathrm{m}^{-1}\right)$ decreased when the EGMA content increased up to $2 \%$. This clear $\gamma_{12}$ decrease agrees with the significant progressive decrease in the dispersed particle size of Figure 5 and indicates a progressive compatibilization. Further increases in the EGMA content did not apparently change $\gamma_{12}$, but it may change slightly, because the estimated error of the measurement was ap-

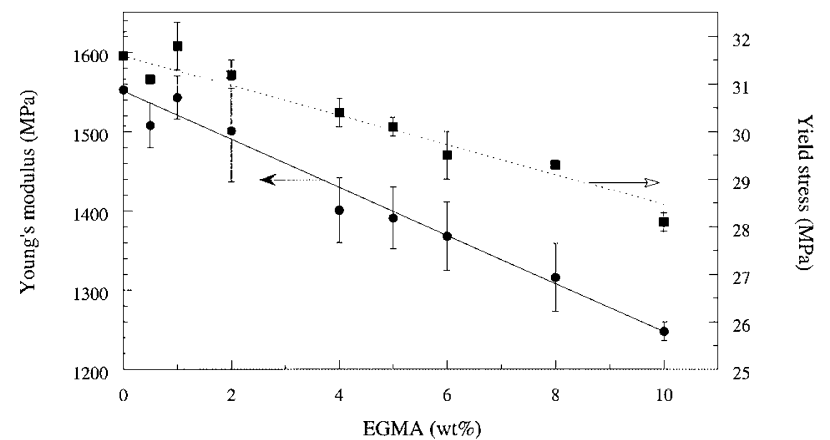

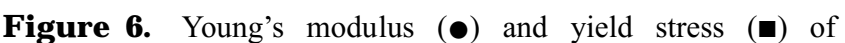
PBT/PEO 80/20 blends as a function of EGMA content.

proximately $20 \%$. These $\gamma_{12}$ values prove that the EGMA presence led to a decrease in $\gamma_{12}$ between the two phases of the blend, and the stable morphologies of Figures $5 \mathrm{c}$ and $5 \mathrm{~d}$. This is due to the presence of reacted EGMA. This indicates that adhesion should increase with the EGMA presence and that a positive effect on the mechanical properties is probable.

\section{Mechanical Properties}

Figure 6 shows the Young's modulus and the yield stress of the blends as a function of the EGMA content. An increase in the EGMA content led to a decrease in both properties, probably due to the elastomeric nature of EGMA. In previous PBT/PEO based blends, ${ }^{3,7}$ the Young's modulus and the yield stress did not change with the compatibilizer level (either grafted maleic an- 


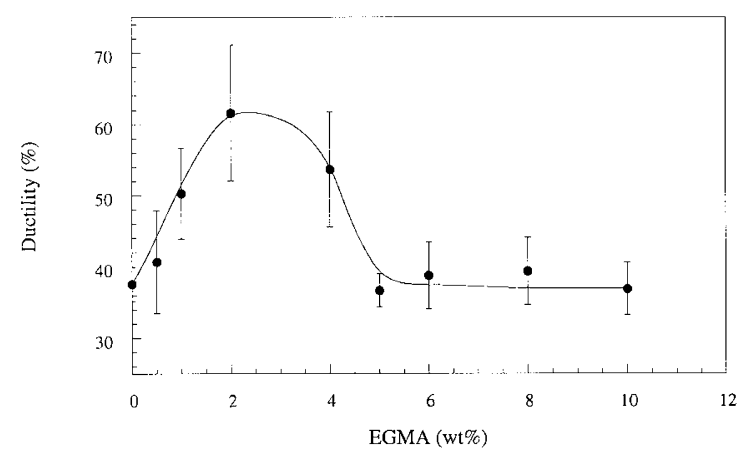

Figure 7. Ductility of PBT/PEO 80/20 blends as a function of EGMA content.

hydride or epoxy resin).

The effects of EGMA on ductility, measured as the elongation at break, are shown in Figure 7. As can be seen, ductility increased with the EGMA content up to $2 \%$ EGMA. At higher EGMA contents, it decreased back to the initial value. This increase in ductility is a positive result, as in previous compatibilized PBT/PEO blends, super-toughness was achieved, but ductility either increased only upon initial compatibilizer addition ${ }^{3}$ or did not change. ${ }^{7}$ The initial increase in ductility upon EGMA addition agrees with that usually seen in blends of thermoplastics, in which the particle size decreases. The decrease in ductility at EGMA contents higher than $2 \%$ is unexpected because a smaller particle size should not have a negative effect on ductility. The change of tendency of $\gamma_{12}$ to values independent of the EGMA content that took place at 2\% EGMA could be responsible for such ductility behavior. Both the increase and the maximum obtained in ductility, at EGMA contents of roughly $2 \%$ indicate that compatibilization took place.

Figure 8 shows the impact strength of the blends as a function of the EGMA content. The large deviation observed in the 80/20-0.5 blend is due to the fact that some specimens were brittle and some ductile. All the blends showed a stress-whitening zone after fracture, that extended from around the notch to the whole fracture surface as the impact strength increased. As can be seen, the impact strength increased very strongly from 165 to $710 \mathrm{~J} \mathrm{~m}^{-1}$, as the EGMA content increased to $2 \%$. Further increases in the EGMA content up to $10 \%$ did not improve the impact strength. These impact strength increases are not due to the presence of the rubbery EGMA in the PBT matrix. This is because it is solved in the PBT matrix, and toughening implies the presence of a separated rubbery phase. The observed impressive increase in impact strength is an additional clear proof of compatibilization, and must be due to the finer dispersion and better adhesion of PBT/PEO blends upon EGMA addition.

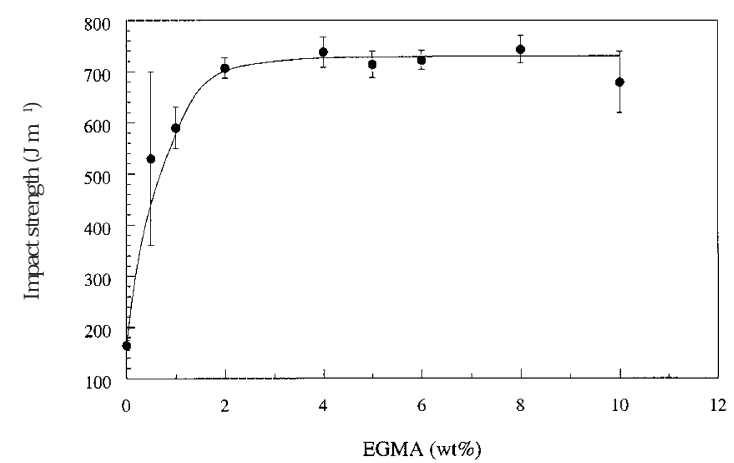

Figure 8. Impact strength of PBT/PEO 80/20 blends as a function of EGMA content.

The impact strength of the 80/20 blend with EGMA contents of $1 \%$ or more is typical of super-tough blends, because it is more than four-fold that of the corresponding blend without EGMA and twenty-fold that of the PBT matrix. This impact strength improvement is larger than the maximum value obtained in PBT/PEO blends modified with either maleinized $\mathrm{PEO}^{1}\left(645 \mathrm{~J} \mathrm{~m}^{-1}\right)$ or epoxy ${ }^{7}\left(575 \mathrm{~J} \mathrm{~m}^{-1}\right)$.

\section{Inter-Particle Distance}

It is known that both the rubber content and the particle size have often been used as parameters that control impact strength in rubber modified blends. ${ }^{1,2,9}$ Subsequently, this was restricted to particle size only, and more recently, ${ }^{14}$ the mean inter-particle distance $(\tau)$ has been proposed $\mathrm{d}^{3,7,8,10}$ as the parameter that controls toughness. $\tau$ is defined as

$$
\tau=\bar{d}_{\mathrm{W}}\left[\left(\frac{\pi}{6 \phi}\right)^{1 / 3}-1\right]
$$

where $\bar{d}_{\mathrm{w}}$ is the weight-average particle size, and $\phi$ is the volume fraction of rubber. Thus, the impact strength increase should occur when $\tau$ between two neighboring particles is below a critical $\tau$ value $\left(\tau_{c}\right)$. $\tau_{\mathrm{c}}$ was proposed to be independent of the particle size and the rubber volume fraction, and characteristic of a given matrix.

To find out whether $\tau_{\mathrm{c}}$ determines the impact strength behavior of PBT/PEO-EGMA blends, the $\tau$ of these blends was calculated using eq 2 and the results are collected in Figure 9 against the impact strengths of the blends. The impact strength of the 80/20-0 blend (outline circle) is also plotted as a reference for low impact strength. The $\tau$ values corresponding to the blends with 0.5 and $1 \%$ EGMA content $(0.40 \mu \mathrm{m}$ and $0.37 \mu \mathrm{m}$ respectively) were not plotted in Figure 9 because, as seen in Table I, adhesion changed ${ }^{7,8,16}$ significantly. Moreover, the plot of Figure 9 has been completed (solid squares) by including the value of a 95/52 blend that corresponds to a study now in progress in 


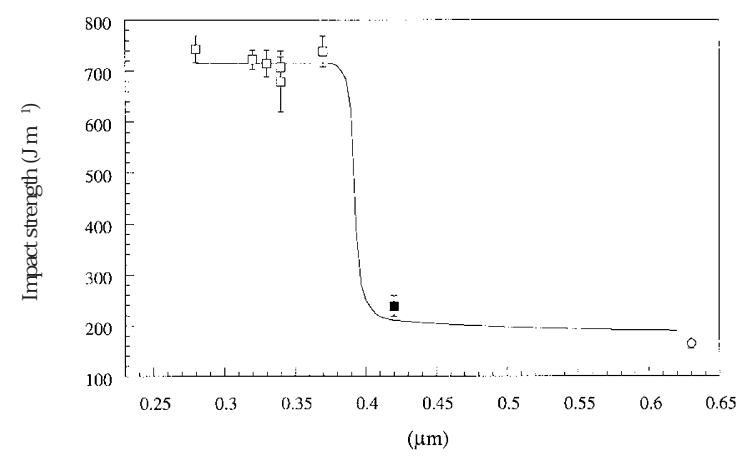

Figure 9. Impact strength as a function of $\tau$ of PBT/PEO $80 / 20$ blends with different EGMA contents (outline square), of the 80/20-0 (open outline circle) and 95/5-2 blends (filled solid square).

our laboratory. As can be seen, the rubber volume fraction did not determine the impact behavior, because at the constant PEO content $(20 \%)$ of this study, there are blends with both low impact strength (80/20-0 blend) and super-tough ones (80/20-2 blend). However, as can also be seen, $\tau$ appears to control the impact behavior, as a sharp increase in impact strength took place when $\tau$ decreased below $0.39 \mu \mathrm{m}$. The value $(0.42 \mu \mathrm{m})$ corresponding to the 95/5-2 blend was in the brittle region, because its impact strength value was not far from that of the $80 / 20-0$ blend. Therefore, $0.39 \mu \mathrm{m}$ is considered to be the $\tau_{\mathrm{c}}$ for PBT in PBT/PEO-EGMA blends.

In agreement with Wu's theory, $\tau_{\mathrm{c}}$ should be a characteristic of a given matrix, ${ }^{6,17,20}$ but different studies have demonstrated that the $\tau_{\mathrm{c}}$ of a blend depends on extrinsic parameters. ${ }^{10,20-24}$ The dependence on intrinsic parameters $3,7,8,10,16,25$ has also been proposed. However, with the exception of adhesion, ${ }^{3,7,8}$ the results are not yet definitive as, besides the studied parameter, another intrinsic parameter usually changed.

Considering the possible intrinsic parameters on which $\tau_{\mathrm{c}}$ and super-toughness depend, the possible dependence of $\tau_{\mathrm{c}}$ on any parameter related to the modulus of elasticity of the components arises. This is because a change in either $E_{\mathrm{m}} / E_{\mathrm{d}}$ or in the modulus of elasticity of either of the two components of the blends leads to the local deformation in the matrix and in the dispersed phase to be different. This should lead to changes of the stress concentrations in the interphase that are the starting point of toughening. In this way, a change of $\tau_{\mathrm{c}}$ with the modulus of the matrix $\left(E_{\mathrm{m}}\right)$ was seen ${ }^{3}$ and the $E_{\mathrm{m}} / E_{\mathrm{d}}$ ratio was proposed ${ }^{3}$ as influencing $\tau_{\mathrm{c}}$. However, a possible dependence of $\tau_{\mathrm{c}}$ upon $E_{\mathrm{d}}$ was not studied. For this reason, the possible dependence of $\tau_{\mathrm{c}}$ upon $E_{\mathrm{d}}$ was tested in Figure 10, by comparing the $\tau_{\mathrm{c}}$ 's of different blends from the bibliography. As can be seen, in the $\tau_{\mathrm{c}}$ range between 0.30 and $0.50 \mu \mathrm{m}$, there is no such dependence, as large changes appeared in $\tau_{\mathrm{c}}$ while $E_{\mathrm{d}}$ remained almost constant. Additional work is in progress

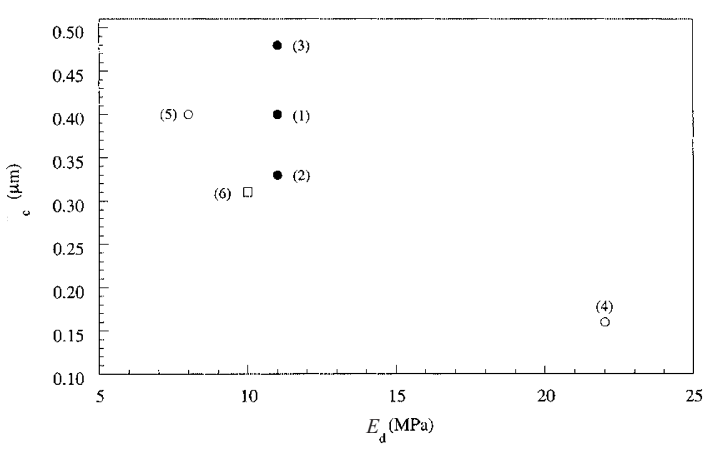

Figure 10. $\tau_{\mathrm{c}}$ as a function of $E_{\mathrm{d}}$ : (1) $\bullet$ : this study; (2) $\mathrm{PBT} / \mathrm{mPEO}^{3}{ }^{3}$ (3) •: PBT/PEO-epoxy; ${ }^{8}$ (4) $\bigcirc:$ PBT/SEBS; ${ }^{10}(5) \bigcirc:$ PBT/ethylene olefin; ${ }^{10}$ and (6) $\square$ : Nylon-6/EPDM ${ }^{21}$ blends.

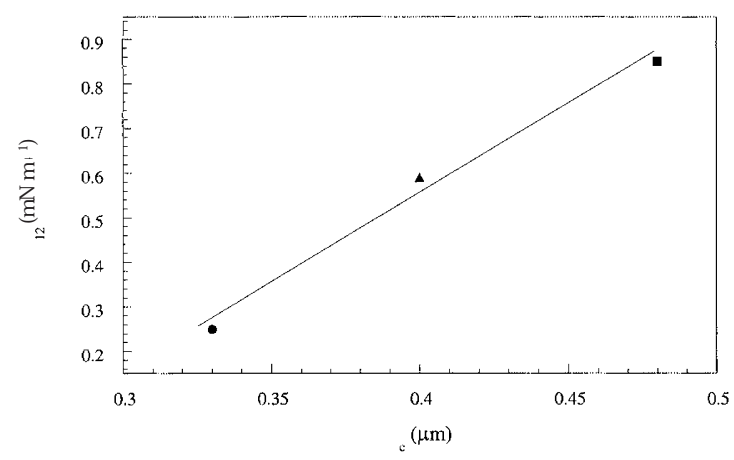

Figure 11. Interfacial tension as a function of $\tau_{\mathrm{c}}$ for PBT/PEO blends compatibilized with EGMA (this study) $(\mathbf{\Lambda})$, anhydride $\operatorname{maleic}^{3}(\bullet)$, and epoxy $\operatorname{resin}^{8}(\boldsymbol{\bullet})$.

in our laboratory to find out whether this lack of dependence can be extended to blends with lower $\tau_{\mathrm{c}}$ values.

The dependence of $\tau_{\mathrm{c}}$ on adhesion is also probable as its level has to influence the conditions for microfracture to start. This study and those of refs 3 and 8 were carried out under the same experimental conditions, and also with the same matrix and rubber. Therefore, with the exception of adhesion, the extrinsic and intrinsic parameters were the same. This allows us to test whether $\tau_{\mathrm{c}}$ depends on adhesion or not, by comparing the $\tau_{\mathrm{c}}$ of this study with those of refs 3 and 8 . This test is represented by Figure 11, in which the $\tau_{\mathrm{c}}-\gamma_{12}$ relationship of this blend and those of $\mathrm{PBT} / \mathrm{mPEO}^{3}$ and PBT/PEO-epoxy ${ }^{8}$ blends are plotted. The differences between the $\gamma_{12}$ values are significant because they are clearly higher than the estimated error $( \pm 20 \%)$ in the measurement. As can be seen, the dependence of $\tau_{\mathrm{c}}$ on $\gamma_{12}$ is clear. Therefore, in the PBT/PEO blends of this study, $\gamma_{12}$, and as a consequence the adhesion between the components, is a parameter that influences $\tau_{\mathrm{c}}$. Additional work is also in progress in our laboratory to quantify this effect in other blends. 


\section{CONCLUSIONS}

PBT/PEO-EGMA blends are composed of two amorphous phases with some partially reacted EGMA. Besides the crystalline PBT phase, another EGMA crystalline phase is observed at EGMA contents equal or greater than 4\%. The reactions of EGMA with both PBT and PEO are slight as they are not detectable by FT-IR but clearly seen as torque increases. The dispersed particle size decreased with the EGMA content in the blends as a consequence of the decrease in the interfacial tension between the components of the blend.

Impact toughness values four-fold that of the corresponding blend without EGMA and twenty-fold higher than that of PBT were obtained. 2\% EGMA is the minimum compatibilizer content that leads to maximum toughness in these super-tough PBT blends. It also gives rise to a maximum ductility and to almost constant values in the modulus of elasticity.

$\tau$ is the parameter that controls toughness in these blends. The transition to super-toughness took place at $\tau_{\mathrm{c}}=0.39 \mu \mathrm{m}$. No dependence of $\tau_{\mathrm{c}}$ on $E_{\mathrm{d}}$ was seen in the observed $\tau_{\mathrm{c}}$ range, but the dependence of $\tau_{\mathrm{c}}$ upon adhesion is inferred by means of the comparison of the $\tau_{\mathrm{c}}$-interfacial tension pairs of this study with those of previous studies on compatibilized PBT/PEO blends.

Acknowledgment. The financial support of the University of the Basque Country (Project number 13 540/2001) is gratefully acknowledged. A. Arostegui thanks the Basque Government for the award of a grant for the development of this work.

\section{REFERENCES}

1. C. B. Bucknall, "Toughened Plastics", Applied Science Publishers Ltd., London, 1977.

2. R. J. Gaymans in "Polymer Blends, vol. 2", D. R. Paul and C. B. Bucknall, Ed., John Wiley \& Sons, Inc., New York, N.Y., 2000, p 177.

3. A. Aróstegui, M. Gaztelumendi, and J. Nazábal, Polymer, 42, 9565 (2001).

4. B. Majumdar and D. R. Paul, in "Polymer Blends, vol. 1", D. R. Paul and C. B. Bucknall, Ed., John Wiley \& Sons, New York, N.Y., 2000, p 539.

5. A. J. Oshinski, H. Keskkula, and D. R. Paul, Polymer, 33, 268 (1992).

6. Z. Z. Yu, M. Lei, Y. C. Ou, G. Yang, and G. H. Hu, J. Polym. Sci., Part B: Polym. Phys., 38, 2801 (2000).

7. A. Aróstegui and J. Nazábal, to be published.

8. A. Aróstegui and J. Nazábal, to be published.
9. W. Hale, J. H. Lee, H. Keskkula, and D. R. Paul, Polymer, 40, 3621 (1999).

10. H. Kanai, V. Sullivan, and A. Auerbach, J. Appl. Polym. Sci., 53, 527 (1994).

11. A. J. Oshinski, H. Keskkula, and D. R. Paul, Polymer, 33, 284 (1992).

12. A. J. Oshinski, H. Keskkula, and D. R. Paul, J. Appl. Polym. Sci., 61, 623 (1996).

13. Z. Z. Yu, Y. C. Ou, and G. H. Hu, J. Appl. Polym. Sci., 69, 1711 (1998).

14. S. Wu, Polymer, 26, 1855 (1985).

15. H. Chen, B. Yang, and H. Zhang, J. Appl. Polym. Sci., 77, 928 (2000).

16. Z. Liu, X. Zhu, L. Wu, Y. Li, Z. Qi, C. Choy, and F. Wang, Polymer, 42, 737 (2001).

17. Z. Bartczak, A. S. Argon, R. E. Cohen, and M. Weinberg, Polymer, 40, 2331 (1999).

18. H. Keskkula and D. R. Paul, in "Rubber Toughened Engineering Plastics", A. A. Collyer, Ed., Chapman \& Hall Ltd., London, 1994, p 136.

19. C. B. Bucknall in "Polymer Blends, vol. 2", D. R. Paul and C. B. Bucknall, Ed., John Wiley \& Sons, Inc., New York, N.Y., 2000, p 83.

20. S. Wu, J. Appl. Polym. Sci., 35, 549 (1988).

21. R. J. M. Borggreve, R. J. Gaymans, J. Schuijer, and J. F. Ingen Housz, Polymer, 28, 1489 (1987).

22. W. Jiang, C. H. Liu, Z. G. Wang, L. J. An, H. J. Liang, B. Z. Jiang, X. H. Wang, and H. X. Zhang, Polymer, 39, 3285 (1998).

23. K. Dijkstra, J. ter Laak, and R. J. Gaymans, Polymer, 35, 315 (1994).

24. W. Jiang, S. C. Tjong, and R. K. Y. Li, Polymer, 41, 3479 (2000).

25. R. J. M. Borggreve, R. J. Gaymans, and J. Schuijer, Polymer, 30, 71 (1989).

26. Y. Pietrasanta, J. J. Robin, N. Torres, and B. Boutevin, Macromol. Chem. Phys., 200, 142 (1999).

27. C. H. Tsai and F. C. Ghang, J. Appl. Polym. Sci., 61, 321 (1996).

28. N. Torres, J. J. Robin, and B. Boutevin, J. Appl. Polym. Sci., 81, 2377 (2001).

29. N. K. Kalfoglou, D. S. Skafidas, J. K. Kallitsis, J. C. Lambert, and L. Van der Stappen, Polymer, 36, 4453 (1995).

30. S. S. Dagli and K. M. Kamdar, Polym. Eng. Sci., 34, 1709 (1994).

31. G. Guerrica-Echevarría, J. I. Eguiazábal, J. Nazábal, Polym. Test., 19, 849 (2000).

32. E. G. Koulouri, A. X. Georgaki, and J. K. Kallitsis, Polymer, 38, 4185 (1997).

33. I. Mondragon and J. Nazábal, J. Appl. Polym. Sci., 32, 6191 (1986).

34. V. Tanrattanakul, A. Hiltner, E. Baer, W. G. Perkins, F. L. Massey, and A. Moet, Polymer, 38, 2191 (1997).

35. V. Tanrattanakul, A. Hiltner, E. Baer, W. G. Perkins, F. L. Massey, and A. Moet, Polymer, 38, 4117 (1997). 